\title{
Tetralogy of Fallot complicated by Pregnancy Induced Hypertension
}

\author{
Abhishek Shrestha, Geeta Gurung, Josie Baral, Ashma Rana
}

TUTH, Kathmandu, Nepal

Tetralogy of Fallot (TOF) is a congenital cyanotic heart disease which, if remains uncorrected by surgery, associated with significant morbidity and mortality. Many patients survive beyond childhood without surgery due to physiological adaptations in the form of shunts. Pregnancy in such patients adds to this physiological demand of the heart.

Women with uncorrected TOF are one of the under reported cases needing good clinical acumen for its timely diagnosis and management as these patients suddenly take a downhill turn during pregnancy. We hereby chose to describe such an uncommon case in our ward, wherein the mother afflicted with TOF was complicated by PIH and subsequently underwent spontaneous premature vaginal delivery with low birth weight neonate.

Tetralogy of Fallot (TOF) is a congenital heart disease(CHD) accounting $5-6 \%$ of congenital malformations, characterized by intra-cardiac right to left shunt due to ventricular septal defect (VSD), overriding of aorta, pulmonary outflow obstruction and right ventricular hypertrophy.

When left uncorrected $25-35 \%$ die in the first year of life, $40-50 \%$ die by the age of $4,70 \%$ by 10 years and $95 \%$ by 40 years. But after corrective surgery $>85 \%$ survive. $^{2}$

A thirty year old G2P1 lady known to have Tetralogy of Fallot, not surgically corrected, was referred to our hospital at $34^{+2}$ weeks period of gestation for persistently elevated BP (blood pressure) with swelling of bilateral lower limbs for 3 weeks. She had quit her diuretic medications about 11 years back without medical advice.
Her first pregnancy was uneventful. She had a normal vaginal delivery at term at home. The child was healthy and free from congenital diseases, especially cardiac disease. In her second pregnancy, she became cyanotic with $\mathrm{SpO} 2$ of $85 \%$ with oxygen via nasal cannula. On further examination she had elevated BP, clubbing and bipedal edema and a systolic murmur in the parasternal area. On pelvic examination the patient was not in labor at the time of admission. She was put on prophylactic antibiotics and anti-hypertensive drugs. Hemoglobin was $9.5 \mathrm{gm} \%$ and her urine albumin was $2+$ while other routine laboratory parameters were within normal limits.

Electrocardiography indicated right ventricular hypertrophy with no evidence of arrhythmia. Echocardiography revealed a large VSD of $\sim 2 \mathrm{~cm}, 35 \%$ overriding of aorta, severe critical PS, RVH and LVEF $\sim 57 \%$. An obstetrical ultrasonographic scan showed no fetal cardiac anomalies but suggested IUGR. Modified bio-physical profile was normal.

Within four hours of admission, patient went into spontaneous preterm labor and had a vaginal delivery without instrumentation. Baby was a preterm male of about 1.3 kilograms with poor Apgar score. After delivery, curettage was done for retained placental bits.

Postpartum period of the mother was uneventful. The neonate, however, developed neonatal sepsis at few hours of birth with many episodes of neonatal seizures and was under intensive care with mechanical ventilation but died after four days.

Poor prognostic factors in TOF include maternal hematocrit greater than $60 \%$, oxygen saturation less 
than $80 \%$, and clinical history of syncopal attacks which is believed to give rise to in-utero growth restriction of $36 \%$ of pregnancies if there is cyanotic heart diseases ${ }^{3}$. Cardiac complications like heart failure, thromboembolic events, coagulopathy, polycythemia, arrhythmias, endocarditis and chronic hypoxia compound the risk obstetrical complications like pre-ecclampsia, ecclampsia, preterm labor and postpartum hemorrhage.

\section{Conclusion:}

This uncorrected case of TOF highlights the need for vigilant monitoring of mother throughout pregnancy. Compounding stress factors on the heart may increase risk of maternal morbidity to mortality. Any complication that arises can compromise the maternoplacental circulation resulting in different adverse fetal outcomes. In our case it was low birth weight baby due to pregnancy induced hypertension and eventually neonatal death.

\section{References}

1. Sankaran VG, and Brown DW. Congenital heart disease. In:Lilly LS, ed. Pathophysiology of heart disease. 4th ed. Baltimore: Lippincott Willimas \& Wilkins; 2007. p. 390-3.

2. Hofman JI. Incidence of congenital heart disease: I. postnatal incidence. Pediatric Cardiology 1995; 16:103-13.

3. A. Srivastava, A. Chaturvedi \& G. Sinha : Pregnancy with Uncorrected Tetralogy Of Fallot : Anaesthetic Management For Cesarean Section. The Internet Journal of Gynecology and Obstetrics. 2009 Volume 12 Number 1.

4. Lake CL, ed. Pediatric cardiac anesthesia, 3rd ed. Stamford, CT: Appleton \& Lange, 1998: 305-306
5. Sawhney H, Suri V, Vashishta K et al. Pregnancy and Congenital Heart Disease - maternal and fetal outcome. Aust N Z J Obst Gyn 1998; 38:266.

6. Perloff JK, Koos B. Pregnancy and congenital heart disease: the mother and fetus. Perloff JK, Child JS. Congenital Heart Disease in Adults. Philadelphia, PA: W. B. Saunders; 1998. p. 44-64

7. Perloff JK. Congenital heart disease and pregnancy. Clinical Cardiology. 1994;17:579587

8. Cunningham FG, Gant NF, Leveno JK. Medical and Surgical Complications in Pregnancy. Williams Obstetrics, $21^{\text {st }}$ edition, 2001, McGraw Hill; 1193.

9. Nollert G, Fischlein T, Bouterwek S, Bohmer C, Klinner W, Reichart B. Long-term survival in patients with repair of tetralogy of Fallot: 36-year follow-up of 490 survivors of the first year after surgical repair. J Am Coll Cardiol 1997;30:1374-83.

10. Uebing A, Steer PJ, Yentis SM, Gatzoulis MA. Pregnancy and congenital heart disease. BMJ 2006; 332:401-6.

11. Sinto R, Nasution SA. Pregnancy in a woman with uncorrected tetralogy of fallot. Acta Med Indones. 2009 Apr; 41(2):81-6.

12. Moore TR, Reiter RC, Rebar RW et al. Repke JT (1993) Hypertension and preeclampsia in Gynecology and obstetrics: a longitudinal approach. eds Moore TR, Reiter RC, Rebar RW, et al. (Churchill Livingstone, New York), pp 463-477.

13. Thilen U, Olsson SB. Pregnancy and heart disease: a review. Eur J Obstet Gynecol Reprod Biol1997; 75:43-50. 